\title{
JUSTIÇA COMO VANTAGEM MÚTUA EM PERSPECTIVA INTERNACIONAL*
}

PAOLO DE RENZIO

A natureza controversa da relação existente entre a moralidade e as relações internacionais já foi objeto de muita discussão no passado, mas a persistência de problemas tais como a forne, a privação e a violência exige uma ampliaçăo e um aprofundamento desse debate. Afinal, o que está em questão não são apenas contendas acadêmicas e sim os fundamentos de decisões políticas que afetam as vidas de milhões de pessoas no mundo inteiro.

Uma categoria muito grande de céticos morais argumentam que totalmente inútil falar de moralidade nas relações internacionais. Para justificar a importância de empregar um enfoque moral de vantagem mútua (que explicitarei adiante) em questðes de justiça internacional, começarei considerando as principais razōes que sustentam tal convicção cética.

Um dos argumentos mais importantes contra a aplicabilidade do discurso moral às relaçōes entre Estados é rotulado "relativismo cultural". Sustenta-se que, uma vez que há tantas culturas diferentes no mundo, cada qual com uma concep̧̧ão potencialmente original sobre o que é a moralidade, jamais será possível chegar a um acordo acerca de uma única concepção de justiça. As tradições e a herança cultural de cada sociedade desempenham um papel muito importante na definiçåo das normas morais que guiam o comportamento de seus membros, e a tentativa de dar forma a uma concepção universal de justiça envolve um risco que não vale a pena

\footnotetext{
* "Justice as Mutual Advantage in International Perspective: Comments on Gauthier and North-South Relations". Texto apresentado na Conferência sobre "Europeizaçăo e teoria política normativa", Oslo, 23-25 de novembro de 1994, organizada pela ARENA (Advanced Research on the Europeanisation of the Nation-State). Tradução de Alvaro de Vita.
} 
correr - 0 de contribuir para algum tipo de "imperialismo moral". O relativismo cultural, dessa forma, priva a moralidade internacional de qualquer significado. ${ }^{1}$

Isso nos leva diretamente a um outro argumento em favor do ceticismo moral nas relaçōes internacionais. Valendo-se de uma frase que Henry Sue emprega para determinar o dever que as pessoas que vivem em países ricos têm de prestar auxílio àquelas que vivem em países pobres, eu denominarei esse argumento "os compatriotas têm prioridade". ${ }^{2}$ sse argumento reflete a crença amplamente difundida de que somente em relação aos membros da própria sociedade existem deveres de prestar auxílio. Tudo o que a moralidade poderia fazer é encorajar a caridade para com os que vivem em pobreza extrema em outros países, ou, no melhor dos casos, estabelecer o dever de não privar qualquer pessoa, inclusive as que são membros de outras sociedades, de seus direitos. Mas nada mais do que isso. Qualquer concepção mais ampla de moralidade somente poderia ser aplicada dentro das fronteiras nacionais, uma vez que os compatriotas realmente têm prioridade.

Um terceiro argumento pela inaplicabilidade de exigências morais ao contexto internacional diz respeito à impossibilidade de criar mecanismos eficientes de sujeição aos acordos internacionais. A ausência de um poder superior ao Estado individual, na política internacional, torna a adesão de cada um dos Estados a qualquer acordo internacional algo puramente instrumental à realizaçăo de objetivos nacionais. Muito dificilinente essa adesão é motivada por uma identificação genuína com os princípios que inspiram o acordo em si mesmo. A obediência a acordos internacionais, assim, jamais se basear em valores morais compartilhados: ela se inspirará sempre em interesses políticos ou econômicos, ou então será ditada pela necessidade de ter boa reputação, e, por isso, também estará sempre sujeita ao risco de defecção por parte daqueles países que deixam de ter um interesse na vigência do acordo. Tudo isso destrói quase toda possibilidade de haver um discurso moral que seja pertinente à política internacional.

As implicações desses argumentos de ceticismo moral para as questões internacionais podem parecer bastante aterrorizantes. Argumentarei, entretanto, que esse não é necessariamente o caso. O importante é que, se o que se deseja é a introdução de exigências de justiça

${ }^{1}$ A única solução possível para isso consiste na identificação de um conjunto mínimo de valores morais compartilhados, se nāo por todas, pela maioria das culturas do mundo, que poderia constituir-se no núcleo de uma concepção comum de justiça. Sobre isso, a literatura conta com inúmeras contribuiçōes destacadas, das quais gostaria de mencionar Alla ricerca dell'ideale, de Isaiah Berlin (Agneili, 1988).

2 Shue, Henry, Basic Rights, Subsistence, Affuence and US Foreign Policy. Princeton, Princeton University Press, 1980, p.131. 
nas relaçōes entre os Estados, qualquer enfoque que objetive alcançar conclusôes precisas, e que não sejam significativas somente para a teoria ideal, terá que levar em conta os interesses efetivos de cada um dos países que participem de um acordo, e as oportunidades de vantagem mútua por ele propiciadas. Isso foi claramente afirmado já nas origens do pensamento moral voltado ao contexto internacional. O próprio Kant, em seu projeto de "paz perpétua", percebeu as motivaçốes que poderiam levar os países a criarem um sistema internacional justo, que evitasse as consequêencias terríveis da guerra e da exploração. Ele as discerniu nos interesses vinculados ao espírito do comércio, e nas vantagens que todos os Estados teriam colocando de lado suas diferenças ideológicas e culturais para, assim, tornar possível a seus membros viver e comerciar em um ambiente internacional justo e pacífico. ${ }^{3}$

O significado da aceitação de um enfoque de vantagem mútua à justiça foi bastante bem analisado por Thomas Scanlon e Brian Barry. ${ }^{4}$ Ambos argumentam que o sentido correto do termo "justiça" está relacionado à imparcialidade, sendo esta a característica que todos reconhecemos como a mais importante em nossa reflexão moral, e sobre isso estou inteiramente de acordo com eles. A imposição da exigência condicional da vantagem mútua à aceitação de princípios de justiça elimina, não há dúvida, boa parte do atrativo que a moralidade pode ter para nós enquanto pessoas morais. Todavia, há situaçōes - e isso se aplica às relações internacionais - em que o apelo vantagem mútua parece ser a única forma de escapar da irrelevância. Para lidar com esses casos, pode ser bastante útil examinar em que medida os princípios de justiça podem também satisfazer exigências de vantagem mútua. Exatamente isso que buscarei fazer, analisando as possíveis aplicações da teoria da justiça como vantagem mútua, de David Gauthier, às relações entre países pobres e ricos.

\section{A TEORIA DA JUSTIÇA DE GAUTHIER}

O objetivo de Gauthier é o de "desenvolver uma teoria da moralidade como parte da teoria da escolha racional". 5 Ele argumenta que os princípios morais devem ser vistos como as restrições racionais à busca do interesse próprio que toda pessoa, com o auxílio da razão, pode reconhecer

${ }^{3}$ Kant, Immanuel. A paz perpétua (tradução italiana, Feltrinelli, 1991, p.56).

4 Scanlon, Thomas. Contractualism and Utilitarianism. In Sen, Amartya \& Williams, Bernard. Utilitarianism and Beyond. Berkeley, University of California Press, 1989; Barry, Brian. Theories of Justice. Berkeley, University of California Press, 1989.

5 Gauthier, David. Morals by Agreement, Oxford, Clarendon Press, 1986, p.2. 
como fundamentadas. Valendo-se de instrumentos emprestados da teoria econômica neoclássica e da teoria dos jogos, Gauthier analisa os padrōes de interaçăo entre indivíduos racionais, interessados unicamente na maximização do próprio bem-estar, para perceber de que forma eles decidem restringir a própria conduta, alcançando assim um acordo que estabelece o fundamento da moralidade. A seguir, delinearei brevemente o argumento principal, de modo a tornar suas pressuposições e conclusões explícitas para os comentários que farei depois.

A primeira coisa que Gauthier faz é estabelecer os limites da moralidade, especificando uma situação em que nenhuma restrição moral seria necessária: o mercado competitivo perfeito. Ressucistando o teorema da mão invisível de Adam Smith, Gauthier argumenta que em um mercado competitivo perfeito, caracterizado pela propriedade privada de bens e de fatores de produção, pelo mercado livre, pela indiferença mútua e pela ausência de externalidades, os conceitos de equilíbrio e de otimalidade viriam a coincidir, tornando-se assim desnecessária qualquer restrição à busca do interesse próprio. Esse é um caso de anarquia moral, em que cada um contribui para o bern social somente pela maximização de seu próprio bem-estar. Do ponto de vista moral, a imparcialidade do mercado é garantida pela ausência de qualquer forma de coerção (mercado livre), pela ausência de benefícios imerecidos ou de custos indesejados (externalidades) e pela eficiência paretiana.

A necessidade de restriçōes morais surge do reconhecimento de que no mundo real a existência de bens públicos e de externalidades quebra o vínculo entre equilíbrio e otimalidade, o que dá lugar a intervençőes corretivas. A moralidade representa, então, uma das possíveis soluçōes para as imperfeições do mercado, e coincide com a disposição de abster-se de tirar proveito de outras pessoas (comportando-se como "carona"), dado que os outros desenvolvem uma disposição idêntica. Gauthier argumenta que "podemos conceber a interação cooperativa como a mão visível que substitui a mão invisível, com o fito de realizar o mesmo ideal que o mercado proporciona em condições de competição perfeita" ${ }^{6}$

A interação cooperativa é descrita, assim, como consistindo de três componentes distintos: (a) um princípio que regula o processo de negociação por meio do qual o excedente social (a produção excedente propiciada pela cooperação) é dividido entre os membros da sociedade, (b) a derivação das condiçōes necessárias à submissão a esse princípio; e (c) a definição de uma posição inicial, a partir da qual a própria negociação tem início. Na visão de Gauthier, a racionalidade igual dos barganhistas leva à 
condição de que a maior concessão que cada um faz, estimada como uma proporção dos interesses do concedente, seja tão pequena quanto possível. Este é o princípio que Gauthier denomina "concessão relativa minimax", que, segundo ele, "captura a idéia de eqüidade e imparcialidade na situação de negociação, e por isso serve de fundamento à justiça ${ }^{H}{ }^{7} \mathrm{~A}$ questão da aceitação ex-post do resultado da negociação é resolvida por Gauthier pelo recurso à distinção entre duas categorias de indivíduos, os "maximizadores puros" e os "maximizadores contidos", sendo estes últimos os indivíduos capazes de desenvolver uma disposição de agir de uma forma cooperativa e de não tirar proveito de outros, desde que os outros façam o mesmo. Gauthier demonstra que, dada uma porcentagem suficientemente elevada de maximizadores contidos em uma população, e supondo-se que a disposição de agir de forma cooperativa encontre uma aceitação suficientemente grande entre eles, a racionalidade de se comportar de forma controlada assegurará a adesão [ao princípio de justiça].

Finalmente, a discussão sobre a posição inicial de negociação impőe-se do reconhecimento de que "somente a partir đle uma posição inicial imparcial é que procedimentos eqüitativos produzem um resultado imparcial", e de que "unicamente se a posição inicial for não-coercitiva, é racional conformar-se com uma negociação e agir de forma cooperativa". ${ }^{8}$ A partir daí, Gauthier impöe uma condição à posição inicial derivada da teoria da propriedade de Locke, segundo a qual "a interação natural, se é que deve determinar a posição inicial de negociação, precisa excluir as atividades que piorem a situaçẫo de qualquer pessoa (...), exceto quando isso é necessário para evitar uma piora na própria situação". 9 A cláusula introduz na interação natural uma estrutura básica de direitos, que garante a cada pessoa uma titularidade básica antes de iniciar-se a negociação. A racionalidade da aceitação da cláusula apóia-se na racionalidade igual dos agentes. Todos esses passos, na visão de Gauthier, combinam-se para dar forma a uma teoria capaz de reconciliar a razẫo e a moralidade, demonstrando-se que é possível chegar a restrições morais à busca do interesse próprio a partir da escolha racional de agentes maximizadores da utilidade.

\title{
GAUTHIER E A JUSTIÇA INTERNACIONAL
}

Depois de ter apresentado os principais argumentos da "moralidade por acordo", analisarei, a seguir, como Gauthier vê a aplicação de sua

\author{
7 lbid., p. 14. \\ 8 lbid., pp.191-2. \\ ${ }^{9}$ Ibid., p.203.
}


teoria às relaçס̃es entre países que se encontram em estágios distintos de desenvolvimento econômico. ${ }^{10}$

Com respeito a isso, Gauthier descreve um mundo hipotético em que existem duas ilhas separadas, habitadas por duas populaçōes diferentes que travaram contato entre si: o povo verde e o povo roxo. Os roxos desenvolveram uma sociedade idealmente justa, regulada por um contrato social que estabelece o respeito à cláusula lockeana e a vigência do princípio de concessão minimax onde quer que o mercado não seja capaz de evitar a existência de externalidades; a eqüidade de longo prazo é garantida por políticas adequadas de população, preservação ambiental e desenvolvimento. O verdes, de sua parte, vivem em um estado de caos, caracterizado por conflitos permanentes e pelo desperdício de recursos. O que ocorreria se os roxos e os verdes viessem a entrar em contato? A cooperação, diz Gauthier, começaria da situação em que as duas populações encontravam-se quando primeiro entraram em contato, uma vez que não haveria violação prévia da cláusula lockeana. Mesmo que a cooperação beneficiasse mais a população menos desenvolvida, porque seria ela que teria mais a ganhar em termos absolutos, isso năo necessariamente levaria a uma redução na desigualdade entre os dois grupos - de fato, é de se supor que os roxos tivessem mais a ganhar do que os verdes em termos relativos. Três tipos de consideraçóes poderiam levar os roxos a estabelecer uma relaçäo cooperativa com os verdes: (a) eles poderiam razoavelmente supor que a longo prazo a cooperação se mostraria de todo modo benéfica; (b) é possível que eles tivessem desenvolvido uma disposição de estabelecer empreendimentos cooperativos com todos os seres humanos, independentemente de nacionalidade ou de nível de desenvolvimento; e (c) e eles poderiam ter um certo grau de compaixão por todos os humanos, manifestando um interesse genuíno pelos interesses de outros, mesmo em isso tendo pouca relação com a escolha racional.

"As relaçōes entre os países mais e menos desenvolvidos de nosso mundo, em aspectos importantes, não săo similares às relações entre os verdes e os roxos", diz Gauthier, mas, para ele, a existência de desigualdades não é indicativa de injustiça. "É possível que as desigualdades estejam crescendo não porque os mais abastados estejam beneficiando-se à custa dos pobres, e sim porque a taxa interna de crescimento da riqueza que, de uma forma justa, os países opulentos podem manter, excede o que está ao alcance dos pobres, e isso mais do que compense os benefícios que a cooperação traz aos países menos desenvolvidos." ${ }^{\text {"1 }}$ No caso de as desi-

10 Ver o cap. 9 de Morals by Agreement, pp. 280-88 sobretudo.

11 lbid., p.287. 
gualdades terem resultado de exploraçấo no passado, é preciso determinar que violaçốes da cláusula lockeana ocorreram e garantir uma compensação adequada. Também é necessário avaliar os padrões atuais de interação para ver se cada país se beneficia dela de uma forma equivalente. "Enquanto nảo pudermos responder a essas questôes (...), não estaremos en condições de avaliar a ordem internacional vigente."12

\section{OS EXCLUÍDOS DA NEGOCIAÇÃO}

Depois de ter mostrado cono Gauthier vê a aplicação de sua tcoria às relações internacionais, tentarei explicitar o que penso serem os problemas mais importantes que surgem quando se confrontam a teoria $\mathrm{e}$ os fatos, para então propor algumas modificações à construção de Gauthier que tornem sua aplicaçĩo mais plausível.

Antes de mais nada, note-se de que forma Gauthier considera que os princípios morais sâo exigências racionais "justas e imp̣arciais" à conduta dos indivíduos. O resultado de uma negociação é moral somente se ela é equiitativa; e ela é equitativa somente se propicia aos participantes uma parcela do excedente produzido pela cooperação que seja proporcional à contribuição de cada um, o que, por sua vez, precisa ser uma função de uma dotaçấo inicial obtida respeitando-se a cláusula lockeana. Consideraçōes de justiça e de equiidade, assim, entram na tcozia de Gauthier em três momentos distintos: na posição inicial, implicando o respeito à cláusula lockeana; no processo de negociação, que deve realizar-se mediante o princípio de concessão relativa minimax; e na teoria da maximização e da obeciiência limitadas, que, valendo-se da suposição da racionalidade igual dos agentes, confere estabilidade e equidade ao contrato.

Antes de tratar de cada unna dessas questōes separadamente, é preciso ver como utma teoria da justiça como vantagem mútua corre o risco de excluir dos benefícios do contrato social todos aqueles que não satisfazem as condições de participação. Gauthier sustenta que "para os maximizadores de utilidade, o vínculo entre a cooperação e a vantagem mútua deve ter precedência sobre o vínculo entre a cooperação e a imparcialidade ou a equiuidade (...). Não abandonamos nem a cláusula [iockeana] nem a obediência restrita [narrow compliance], mas as subordinamos à exigência de vantagem mútua". ${ }^{13}$ A conseqüência direta disso é a completa exclusāo daqueles que não têm pouco ou nada a oferecer no mercado em termos de 
contribuição à geração de um excedente resultante de cooperação. No caso das relaçŏes Norte-Sul, isso poderia significar que una boa parte da África Sub-Saariana, juntamente com outras das regiőes mais pobres do planeta, seriam abandonadas à própria sorte. Esse ponto foi energicamente criticado por Brian Barry e por David Braybrooke, ambos considerando que a teoria de Gauthier se detém muito longe de inúmeras de nossas intuições morais ${ }^{14}$ e nada tem a dizer com respeito à "igualização" ou à "satisfação de necessidades" (aspas de Gauthier). "Tudo o que se exige [na teoria de Gauthier] é que a pobreza de um não tenha sido criada por atividades ilícitas da parte de outro. A pobreza causada pela incapacitação jamais violar essa cláusula."15 Mesmo introduzindo argumentos fortes contra a aplicabilidade da "moralidade por acordo" às relações Norte-Sul, é claro que essa crítica não invalida a teoria. Passo agora às questôes mais específicas indicadas acima.

\section{PROBLEMAS E COMENTÁRIOS}

A primeira questão a ser considerada diz respeito à cláusula lockeana. Sobre isso, a única (e quase trivial) observação a ser feita, a de que as atuais relaçóes Norte-Sul a desrespeitam claramente, uma vez que a maioria dos países subdesenvolvidos do Sul foram colônias dos países ri$\cos$ do Norte. Isso quer dizer que a utilização da coerção e da exploração fez parte das relaçóes entre uns e outros, sobretudo no que se refere à espoliação de recursos importantes dos primeiros. Dessa forma, a violação da cláusula já de início elimina a possibilidade de fundamentar as relações Norte-Sul em um contrato social equitativo e mutuamente vantajoso, considerando-se a evidente impossibilidade de restaurar as condições de uma posição inicial imparcial, o que exigiria que as ex-metrópoles restituíssem todas as rendas coloniais.

Kraus e Coleman apontaram duas formas pelas quais a desigualdade da posição inicial pode transmitir-se para o resultado da negociação. ${ }^{16}$ Em primeiro lugar, uma dotação inicial maior obtida por meio do uso da força pode possibilitar que seu possuidor contribua em maior

14 Uma das passagens de Gauthier que ambos criticasn é a seguinte: "o homem rico tem o direito de se banquetear com caviar e com champanhe, enquanto à sua porta a mulher miserável passa fome. Mesmo que para ela não sobrem nem mesmo as migalhas da mesa do homem rico, se isso o privar do prazer de usá-las para alimentar seus pássaros". Gauthier, ibid., p.218. 15 Barry, B. op. cit., p.249; Braybrooke, David. "Social Contract Theory's Fanciest Flight". Ethics 97 , julho de 1987.

${ }^{16}$ Kraus \& Coleman, J. "Morality and the Theory of Rational Choice". Ethics 97, Julho de 1987. 
proporção para o excedente gerado pela cooperação, o que lhe garante uma recompensa maior. Segundo, aqueles que violam a cláusula lockeana podem, graças a sua superioridade na posição inicial, obter uma parcela desproporcional do excedente cooperativo por meio da coerção e da extorsão, o que invalida a eqüidade não só da posição inicial mas também do próprio processo de negociação. Considerando este último caso, é interessante ver como as conclusões a que leva lembram bastante os argumentos que faziam parte das teorias estruturalistas e da teoria da dependência, que explicavam as desigualdades na distribuição internacional da renda como um resultado de relações de comércio injustas e distorcidas. Uma interpretação à luz das considerações acima veria os países ricos como colhendo suas vantagens maiores graças à apropriação injusta de recursos durante o período colonial, o que thes conferiu um poder maior de negociação e os meios para impor práticas de comércio injustas que lhes asseguram uma parcela desproporcional do excedente gerado pela integração internacional.

Finalmente, um último ponto da teoria de Gauthier que merece atenção diz respeito à racionalidade da obediência restrita, ou da disposição de se aceitar somente negociações (quase) ótimas e (quase) eqüitativas. Como vimos, a hipotese fundamental de Gauthier sobre isso é a da racionalidade igual dos agentes. O que ocorreria se certos fatores externos interviessem impossibilitando a racionalidade igual, quebrando-se, dessa forma, o vínculo entre razão e moralidade? O próprio Gauthier menciona três desses fatores: o fator ideológico, concernente às crenças que afetam os termos de cooperação de uma forma injusta; o fator histórico, que diz respeito, mais do que a crenças, às instituiçōes e práticas que determinam os direitos que as pessoas podem exercer na interação; $\mathrm{e} o$ fator tecnológico, que coloca os possuidores de tecnologias avançadas em uma posição de ditar os termos da interação com os seus semelhantes. É claro que esses fatores podem constituir um argumento muito forte pela inaplicabilidade da teoria de Gauthier às relaçőes Norte-Sul.

É possível conceber pelo menos duas formas pelas quais os fatores ideológicos e históricos podem limitar a racionalidade dos agentes. De uma parte, uma ideologia baseada em normas estritas (como, por exemplo, a ideologia do Islã) pode tentar impor certos tipos de resultados, seja acenando com uma retirada da negociação seja produzindo uma assimetria nos níveis de adesão exigidos de todos os participantes da negociação. De outra parte, o baixo nível de educação, causado por fatores históricos, pode levar um participante a submeter-se "racionalmente" a um acordo injusto, simplesmente por estar disposto a obter qualquer parcela que seja do excedente, sem se dar conta que poderia exigir uma parcela 
maior. Os fatores tecnológicos parecem ser ainda mais perigosos, porque não se baseiam em características culturais quase incontroláveis e sim representam a propria racionalidade aplicada à utilização de recursos escassos. "A tecnologia é poder" diz Gauthier, e "uma tecnologia superior capacita seus possuidores a racionalmente preservarem certas disposiçōes institucionais, exigindo que outros racionalmente aquicsçam a elas, ainda que, numa clara violaçăo à cláusula [lockeana], elas tenham por base direitos diferenciados". ${ }^{17} \mathrm{E}$ as imensas diferenças de desenvolvimento científico e tecnológico existentes entre o Norte e o Sul parecem aprofundar ainda mais o fosso entre a razăo e a moralidade.

Como, possível, então, aplicar a teoria da moralidade por acordo a justiça internacional sen ignorar todos os problemas mencionados acima? Argumentarei que seria possível eliminar algumas das lacunas existentes entre a teoria ideal e o mundo real alterando-se algumas das hipóteses de Gauthicr. É claro que isso significa não levar em conta os objetivos originais de Gauthier, mas acredito que de todo modo a tentativa vale a pena.

Consideremos, una vez mais, a cláusula lockeana. Na teoria de Gauthier, essa cláusula estabelece um conjunto mínimo de direitos negati. vos que protege todos os indivíduos que tomam parte de unna interaçăo cooperativa, assegurando que não se tirará proveito de nenhum deles. Tudo isso, como já foi dito, está sujeito à exigência de que exista uma possibilidade de vantagem mútua.

Para evitar os problemas que mencionei acima, essa forma de entender a cláusula é certamente insuficiente, sobretudo no caso das relações Norte-Sul. O que parece imprescindível é uma modificaçāo da cláusula, de forma que ela leve em conta nossa intuição moral de que todos os homens devem ser tratados com igualdade, independentemente da capacidade que tenham de oferecer alguma vantagem na interação com outros e de sua contribuição para a geração de um excedente cooperativo. Tal modificação, a meu ver, deveria ser no sentido de atribuir a cada indivíduo um conjunto mais amplo de direitos, incluindo os dircitos positivos dos pobres à nutrição adequada, à assistência médica, à educação, e assim por diante, de um ponto de vista similar ao da "satisfação de necessidades básicas". A justificação dessa modificação poderia vir de dois tipos de argumentos, un deles concernente aos conceitos de utilidade e de bem-estar e o outro concernente à possibilidade de reintroduzir essa modificação em una perspectiva de vantagem mútua.

A introdução de um conjunto mais amplo de direitos (positivos) na cláusula lockeana requer, acredito, o abandono da noção de utilidade 
(seja no sentido de "satisfação de desejos", seja no de "obtenção de prazer"), empregada por Gauthier como a melhor representaçāo do bem-estar individual. ${ }^{18}$

James Griffin, en seu livro Well-being, discute essas questōes de uma forma bastante interessante. ${ }^{19}$ Ele desenvolve um enfoque ao conceito de bem-estar em passos sucessivos que levam a uma teoria perfeccionista (do bem-estar) fundada na prudência moral. O primeiro passo é uma apreciação das concepçōes utilitárias do bem-estar baseadas en desejos efetivos (as "preferências manifestas" do economista) - säo as concepções que apelam à soberania do consumidor e à autonomia dos agentes. A falta de informação e as deficiências lógicas podem resultar na formação de desejos que não produzem uma satisfação efetiva. Pode-se então argumentar que a utilidade consiste na satisfaçåo dos desejos que as pessoas teriam se percebessem a verdadeira natureza do objeto desses desejos. Isso nos conduz ao segundo passo na definição do bem-estar, dessa vez baseada em desejos informados e não em desejos efetivos. A informaçāo dá lugar a uma hierarquização dos desejos, de acordo com a medida em que cada un deles permite levar adiante nossos planos de vida: podemos ter desejos imediatos (por exemplo, o de tomar uma bebida), mas também temos os de ordem superior (digamos, o de distanciar-se dos desejos de consumo material) e os desejos globalizantes (digamos, o de viver a própria vida autonomamente). Nessa linha, Griffin gradualmente distancia-se das concepçőes utilitárias, argumentando que não é possível acomodá-las razoavelmente na teoria moral.

Em busca de um enfoque mais objetivo ao bem-estar, o passo seguinte consiste em tentar defini-lo em termos de necessidades. As pessoas têm necessidades, diz Griffin, devido aos objetivos e aos fins que estão procurando realizar. E elas são de dois tipos. Algumas são instrumentais: são as necessidades que as pessoas têm em razão dos fins que escolheram. Outras, entretanto, são básicas: são as necessidades que todos temos simplesmente porque somos humanos. $\mathrm{O}$ bem-estar pode então ser definido como o grau em que necessidades básicas são satisfeitas, pelo menos quando se trata de realizar comparaçōes interpessoais do ângulo da avaliação moral. Mas, e isso nos leva ao último passo de Griffin, por que se conformar com meios (sejam desejos subjetivos ou necessidades objetivas) se poderíamos definir o bem-estar diretamente em termos dos fins que cada pessoa quer realizar? As preferências, como nossa experiência

18 De lato, Gauthier define os indivíduos racionais como maximizadores da utilidade esperada.

19 Griftin, James. Well-being: Its Meaning, Meosurement and Moral Inportance. Oxford, Clarencion Press, 1986. 
psicológica também evidencia, não devem ser determinadas por puros gostos, inclinações pessoais ou necessidades, e sim devem também incorporar uma percepção de certo conjunto de valores que constitui um "ideal da boa vida" válido para a humanidade como um todo. Como isso pode ser definido e servir a nossos objetivos?

Griffin elabora uma interessante versão de perfeccionismo, que define os fins da vida humana a partir de uma teoria prudencial do valor. Uma concepção como essa, argumenta, é capaz de incorporar o significado moral do bem-estar. O perfeccionismo, sustenta Griffin, "afirma haver uma forma ideal a ser assumida pela vida humana, uma forma em que a natureza humana floresce $\mathrm{e}$ atinge a perfeição. E ele oferece uma teoria do bem-estar notavelmente diferente das concepções baseadas quer em desejos quer em necessidades: o nível de bem-estar de qualquer pessoa é diretamente proporcional a quão próximo a vida dessa pessoa chega desse ideal" ${ }^{20} \mathrm{E}$ o proprio ideal consiste no tipo de vida que prudencialmente é mais valioso. Nessa perspectiva, a racionalidade prática nada tem a ver com o conteúdo da vida ideal, coincidindo com a capacidade de determinar o que ela deve ser.

A racionalidade, para Griffin, levaria à escolha da seguinte lista de fins, ditada pela prudência: (a) a (auto-)realização; (b) os componentes fundamentais da existência humana (a autonomia, as capacidades básicas, a liberdade, tanto negativa quanto positiva); (c) o entendimento $\mathrm{e}$ o conhecimento; (d) o desfrute de prazeres; e (e) relaçőes pessoais fortes. ${ }^{21}$ Tudo isso săo coisas prudencialmente valiosas que constituem o que concebemos como uma boa vida. É claro que se pode achar que a lista não é exaustiva, ou que é excessivamente ampla, mas essas são considerações que estão além do escopo de minha discussão. E também é claro que não há uma combinação única dos diferentes fins. Essa combinação provavelmente variará de pessoa para pessoa, uma vez que, ademais de conferirem pesos diferentes a fins diferentes, os indivíduos também possuem diferentes capacidades e habilidades e as combinam de muitas formas distintas.

Uma vez que essas considerações são vistas como um fundamento plausível a partir do qual trabalhar, a ênfase colocada na racionalidade prática e nas diferenças entre os indivíduos novamente requer a definição de padrões mais precisos de avaliação do nível de bem-estar que uma pessoa pode atingir. Com respeito a isso, Amartya Sen vem contribuindo para esclarecer algumas questōes diff́ceis. Sen está de acordo com Griffin na rejeição ao utilitarismo, uma vez que este parece estar longe de 
oferecer uma medida adequada do nível de bem-estar, considerando as pessoas como "meros locais onde uma coisa denominada 'felicidade' ocorre, sem perguntar por suas origens, causas e conseqüências, e sem se importar com o fato de que essa coisa possa ser compartilhada por muitos ou somente por alguns poucos" 22 . O "enfoque das capacidades" proposto por Sen abre espaço para uma forma mais abrangente de conceber a avaliação do bem-estar. Não farei um exame detalhado desse enfoque. Basta mencionar, para os nossos propósitos no momento, que ele se apóia na suposição de que as pessoas dispõem de capacidades diferentes de converter os bens que têm à disposição em bem-estar efetivo. O bem-estar deve entäo ser avaliado como a capacidade de "viver bem", em termos do que a pessoa é capaz de fazer ou é capaz de ser. Nessa perspectiva, a efetivação de capacidades básicas substitui a satisfação de necessidades básicas como o critério objetivo para medir níveis de bem-estar. Além disso, as capacidades básicas não são entendidas como fins em si mesmos e sim como meios para a realização de algum ideal da boa vida. ${ }^{23}$

A combinação dos enfoques propostos por Sen e Griffin, com vistas à definição de um substituto para a cláusula lockeana, dá forma a um conjunto de direitos cuja ênfase está na igualização das capacidades básicas dos agentes, incluindo as pessoas que vivem na pobreza e têm muito pouco a oferecer no mercado internacional. Assim, ao invés de tentar introduzir complicados elementos de altruísmo em uma concepção utilitária de bem-estar, o enfoque esboçado acima põe força na racionalidade de se propiciar direitos positivos mais amplos aos habitantes de países subdesenvolvidos, mesmo que isso implique custos que deverão recair sobre os países ricos. Todas essas considerações se farão presentes se o que se quer é enfrentar os problemas que surgem, em uma teoria como a de Gauthier, com respeito ao processo de negociação e à estabilidade do contrato.

O segundo argumento pela modificação da cláusula lockeana, no sentido da inclusão de direitos positivos, vem da ameaça potencial que os países pobres representam para os ricos. Pode-se facilmente imaginar que, se a situação não se alterar substancialmente nas próximas décadas, os países pobres poderão representar um enorme perigo de muitas formas diferentes. Primeiramente, há os fluxos de migração, que, se já são intensos, aumentariam ainda mais, submetendo os países receptores ricos a pressões cada vez mais fortes. $\mathrm{O}$ terrorismo e a subversão poderiam aumentar por razões políticas e econômicas. Por fim, a pressão sobre os re-

${ }^{22}$ Sen, Amartya. Resources, Values and Development. Oxford, Blackwell, 1984.

23 As referências mais importantes ș̃o A. Sen, Commodities and Capabilities (Amsterdam, North Holland, 1985)e The Standard of Living (Salt Lake City, University of Utath Press, 1992). 
cursos naturais em países subdesenvolvidos poderia causar desastres ambientais inimagináveis. Pode não ser correto chamar isso de "vantagem mútua", mas é certo que essas ameaças poderiam convencer o Norte abastado a suportar os custos de uma ampliação do escopo da cláusula lockeana, garantindo-se os direitos positivos básicos aos países "marginais", e os custos de uma reorganização das normas da cooperação internacional.

Finalmente, no que diz respeito à racionalidade da adesão (aos termos da cooperação), duas observações me vêm à mente. Como vimos, há fatores históricos e ideológicos que contribuem para quebrar o vínculo entre razão e moralidade. No contexto das relaçōes Norte-Sul, uma especial relevîncia deve ser dada ao fato de que os habitantes dos países subdesenvolvidos podem não ter a capacidade de avaliar as possibilidades que a cooperação internacional thes oferece. Isso requer a inclusão, na posição inicial, de um direito à educação básica, que permitiria aos habitantes dos países pobres desenvolverem uma disposição coerente de somente respeitar os acordos que considerem "equitativos e vantajosos", reduzindo-se a distância, dessa forma, entre níveis diferenciados de racionalidade.

Os fatores tecnológicos constituem um problema mais difícil de ser enfrentado, uma vez que não é de racionalidade que se trata aqui. A única saída passa por considerar a possibilidade de aquiescência por parte dos países pobres, que aceitariam um acordo menos do que equititativo, propiciando aos países ricos uma parcela maior do excedente, para dessa forma levar a negociação a um bom termo. De toda forma, a parte pior situada "năo ignora a vantagem que concede a outras com sua aquiescência, e está sempre pronta a retirá-la, e a exigir uma estratégia conjunta que the seja mais favorável, se acreditar que tal estratégia não tornaria a cooperação desvantajosa para as demais partes (...) A cooperação com base em termos menos do que justos, por isso, é menos estável, por não conquistar a adesão plena de todos os participantes. ${ }^{24}$ Essa solução parcial, mesno năo sendo justa, tornaria a cooperação Norte-Sul possível en termos distintos de um mero equilíbrio de poder.

As observações contidas neste artigo esboçam a possibilidade de aplicar a teoria de Gauthier da "moralidade por acordo" às relaçóes entre os países ricos e pobres. Pode parecer que as modificaçōes propostas subvertem o propósito original de Gauthier - o de construir uma teoria da justiça como vantagem mútua baseada na racionalidade da conduta moral --, reintroduzindo exigências fortes de imparcialidade na cláusula lockeana, precisamente ali de onde Gauthier decidira excluí-las. Mas enquanto os argumentos em prol da justiça distributiva internacional baseados em con-

24 Gauthier, op. cit., p.230. 
sideraçōes de imparcialidade ainda estão longe de serem exequíiveis, ${ }^{25}$ dadas as restriçōes que se impõem às decisões políticas e econômicas, os argumentos baseados na vantagem mútua, de sua parte, não levam em conta os problemas criados pelos que são pobres demais para terem algo a oferecer no mercado mundial. Em outros termos, ençuanto a imparcialidade vai longe demais, a vantagem mútua é insuficiente para oferecer uma concepção aceitável de justiça que seja aplicável a um contexto internacional caracterizado por pesadas diferenças de níveis de bem-estar.

Acredito que os esforços de pesquisa devem focalizar exatamente os vínculos existentes entre os argumentos de imparcialidade es argumentos de vantagem mútua no contexto das relações Norte-Sul, tentando aleançar o limite até onde podemos levar nossas intuições morais imp̧arciais sem privá-las do apelo à vantagem mútua que parece ser indispensável em um mundo constituído de Estados permanentemente divididos entre o conflito e a cooperação.

PAOLO DE RENZIO é pesquisador do Centro di Ricerca in Etica Affari, delle Professioni e della Politica, Istituto Scientifico Sin Raffaele, Milño.

25 Ver, por exemplo, as discussões de Brian Barry em Liberty and thrstice (Oxford, Oxford University Press, 1989), de Charles Beitz em Political Theory and International Relations (Princeton, Princeton University Press, 1979) e de Thomas Pogge em Realizing Raw/s (Cornell University Press, 1989). 


\section{JUSTIÇA COMO VANTAGEM MÚTUA EM PERSPECTIVA INTERNACIONAL}

Discutem-se a pertinência e as implicações do contratualismo proposto pelo filossofo canadense David Gauthier à análise das relaçőes internacionais. Argumenta-se que substanciais alterações na teoria de Gauthier da "moralidade por acordo" seriam necessárias para que se levem em conta os interesses daqueles que pouco ou nada têm a oferecer no mercado em termos de contribuição à geração de um excedente produzido por cooperaçăo.

\section{JUSTICE AS MUTUAL ADVANTAGE IN INTERNATIONAL PERSPECTIVE}

The application of David Gauthier's contractualism to the analysis of international relations is examined. It is argued that substantial changes in Gauthier's theory of "morality by agerement" would be necessary to take into account the interests of those who have little or nothing to offer in the market concerning contributions to the creation of a surplus through cooperation. 